\title{
Mesenchymal stem cell transplantation ameliorates Sjögren's syndrome via suppressing IL-12 production by dendritic cells
}

Bingyu Shi ${ }^{1+}$, Jingjing $\mathrm{Qi}^{1 \dagger}$, Genhong Yao ${ }^{1 *}$, Ruihai Feng ${ }^{1}$, Zhuoya Zhang ${ }^{1}$, Dandan Wang ${ }^{1}$, Chen Chen ${ }^{1}$, Xiaojun Tang ${ }^{1}$, Liwei Lư ${ }^{2}$, Wanjun Chen ${ }^{3}$ and Lingyun Sun ${ }^{1 *}$

\begin{abstract}
Background: Mesenchymal stem cells (MSCs) have been demonstrated to be effective in treating autoimmune diseases including Sjögren's syndrome (SS). We aim to compare the effects of MSC transplantation (MSCT) and the role of serum interleukin-12 (IL-12) in SS.

Methods: IL-12 levels were measured by ELISA. IL-12 mRNA transcripts in dendritic cells (DCs) were determined by RT-PCR. After co-culturing with MSCs, IL-12 mRNA transcripts in mouse and human DCs were detected. Non-obese diabetic (NOD) mice received MSCT, recombinant IL-12, or anti-IL-12 mAb treatment, respectively. Then, salivary flow rates, histopathology of salivary glands, and splenic lymphocyte subsets were examined in these mice.

Results: IL-12 levels in the serum were significantly increased in SS patients and positively correlated with the EULAR 2010 Sjögren's syndrome disease activity index. DCs from SS patients produced more IL-12 than those from the control. Likewise, IL-12 treatment in NOD mice significantly decreased salivary flow rates and promoted lymphocyte infiltration in salivary glands. IL-12 antibodies downregulated Th1, Th17, and Tfh cell. MSCT enhanced salivary flow rates and decreased lymphocyte infiltrations in salivary glands of NOD mice. MSCT downregulated Th17 and Th cells but upregulated regulatory T cells. MSCT reduced IL-12 productions in both SS patients and mice.
\end{abstract}

Conclusion: Our results indicate that MSCs ameliorate SS possibly via suppressing IL-12 production in DCs and that IL-12 could be a potential therapeutic target of SS.

Trial registration: NTC00953485. Registered June 2009.

Keywords: Mesenchymal stem cells, Sjögren's syndrome, Interleukin-12

\section{Background}

Mesenchymal stem cells (MSCs), derived from either the bone marrow (BMMSCs), umbilical cord (UCMSCs), or adipose tissues (ADMSCs), have been shown to be effective in treating various autoimmune diseases, including systemic lupus erythematosis (SLE), rheumatoid

\footnotetext{
* Correspondence: yaogenhong@126.com; lingyunsun@nju.edu.cn ${ }^{\dagger}$ Bingyu Shi and Jingjing Qi contributed equally to this work. ${ }^{1}$ Department of Rheumatology and Immunology, The Affiliated Drum Tower Hospital of Nanjing University Medical School, Nanjing, China Full list of author information is available at the end of the article
}

arthritis (RA), and inflammatory bowel disease (IBD) [1-4]. However, much less is known about the effects of MSCs in treating Sjögren's syndrome (SS). In mice with radiation-induced xerostomia, MSC transplantation (MSCT) has been found to reduce apoptotic cell rates in salivary glands (SG) and increase functional acini, thus ameliorating salivary damages $[5,6]$. Several studies have reported the use of BMMSCs in treating SS. Khalili et al. reported that BMMSCs could prevent saliva secretion loss and reduce lymphocytic influx in salivary glands in non-obese diabetic (NOD) mice [7]. Our previous studies show that SS patients with poor response to

(c) The Author(s). 2018 Open Access This article is distributed under the terms of the Creative Commons Attribution 4.0 International License (http://creativecommons.org/licenses/by/4.0/), which permits unrestricted use, distribution, and 
glucocorticoid or glucocorticoid combined with immunosuppressive drugs could also benefit from UCMSC transplantation [8]. These data provide strong evidences for the advantages of MSCT application in treating SS patients. However, the mechanisms underlying the beneficial effects of MSCs on SS are not fully elucidated.

IL-12 is a pro-inflammatory cytokine mostly produced by dendritic cells (DCs) [9]. IL-12 acts as a pro-inflammatory cytokine because of its capacity to induce $\mathrm{T}$-bet and promote naïve $\mathrm{T}$ cell differentiation into Th1 cells. It was reported that overexpression of IL-12 in submandibular gland of autoimmune-prone SJL mice contributed to the manifestation of SS-like symptoms and that the mice displayed age-dependent increase in anti-SSB/La and anti-nuclear antibodies [10], which suggested IL-12 might accelerate the pathogenesis of SS. However, the mechanism of IL-12 on SS remains incompletely understood. Apart from inflammatory infiltrates in salivary glands, Sjögren's syndrome is also a disease with lymphocytic proliferation disorders. For example, it has been reported that Th1, Th17, and Tfh cells were highly elevated in SS patients, while Th2 and Treg cells were decreased [11-14]. The NOD mice displayed similar lymphocyte alterations to SS patients [8]. Thus, we aimed to study the effects and mechanisms of IL-12 on SS focusing on the local infiltrates and changes of lymphocyte subsets.

MSCs possess strong immuno-regulatory functions [15]. In addition to regulating $\mathrm{T}$ and $\mathrm{B}$ cells, MSCs are also capable of regulating DCs [16-19]. It was reported that MSCs strongly inhibited the differentiation of peripheral monocytes into DCs via prostaglandin E2 (PGE2) [20]. Moreover, MSCs could also downregulate the expression of activation markers such as MHC-II, CD86, and CD40 on DCs [21]. Co-cultures with MSCs and DCs increased the generation of IL-6, IL-10, and CXCL8 but decreased TNF- $\alpha$, IFN- $\gamma$, and CXCL10 in DCs [16]. However, how MSCs regulate the generation and function of DCs in SS remains unknown.

In this study, we aimed to explore the effects of MSCT and the role of IL-12 in SS.

\section{Methods}

Isolation and culture of UCMSCs and fibroblast-like synoviocytes (FLS)

Fresh umbilical cords of newborn babies and synovial tissues from human knee joints were obtained from The Affiliated Drum Tower Hospital and were processed immediately. Protocols for isolation and culture of UCMSCs and FLS were described previously [22, 23]. Passages 3-5 UCMSCs and FLS were used in this study. The protocols were approved by the Ethics Committee at the Drum Tower Hospital of Nanjing University Medical School.

\section{Mice}

Female NOD(ltj) mice at 8-12 weeks of age obtained from the Model Animal Research Center of Nanjing University were used for studying experimental Sjögren's syndrome. All animal experiments were approved by the Ethics Committee of the Affiliated Drum Tower Hospital of Nanjing University Medical School. The 8-week-old mice were injected with one million human UCMSCs, FLS, or the same volume of sterilized phosphate-buffered saline (PBS) via tail vein, respectively. In separate experiments, 12-week-old NOD mice were injected intraperitoneally (i.p) with murine recombinant IL-12 proteins (40 ng/g body weight, IL-12 group) or anti-IL-12 monoclonal antibody $(4 \mu \mathrm{g} / \mathrm{g}$ body weight, anti-IL-12 group) or same volume of sterilized PBS. Five mice were used for each group. All mice were sacrificed at 13 weeks of age.

\section{Patients and healthy controls}

Twenty-nine SS patients and age- and sex-matched healthy controls $(\mathrm{HC})$ were studied. All SS patients fulfilled the American-European Consensus Group criteria for primary SS diagnosis [24]. We scored the disease activity index of each patient according to the EULAR 2010 Sjögren's syndrome disease activity index (ESSDAI) criteria [25]. For comparing serum IL-12 levels before and after MSC transplantation, 10 SS patients were studied. UCMSCs $\left(1 \times 10^{6} / \mathrm{kg}\right.$ of body weight) were administrated by intravenous infusion. Whole blood was taken before and 7 days post MSCT. This protocol was approved by the Ethics Committee at the Drum Tower Hospital of Nanjing University Medical School and registered at http://www.clinicaltrials.gov (NTC00953485). All patients provided informed consent. Detailed clinical features about SS patients who received MSCT were listed in Additional file 1: Table S1.

\section{Measurement of saliva flow}

The saliva flow rates were measured as previously described [26]. Briefly, mice were anesthetized by i.p injection with $10 \%$ chloral hydrate at a dose of $100 \mathrm{ml} / \mathrm{kg}$ body weight. After $5 \mathrm{~min}$, anesthetized mice were induced for saliva secretion by i.p injection of $5 \mathrm{mg} / \mathrm{kg}$ pilocarpine (Sigma-Aldrich), and then a $20-\mu \mathrm{l}$ sized pipet tip was used to collect saliva from the oral cavity for $10 \mathrm{~min}$ at room temperature.

\section{Flow cytometry analysis}

For detection of mouse Th1, Th2, and Th17 cells and expression of IL-12 in human DCs, mouse splenocytes or human PBMCs were first stimulated with phorbol 12-myristate 13-acetate (PMA) $(50 \mathrm{ng} / \mathrm{ml})$, ionomycin $(1 \mu \mathrm{g} / \mathrm{ml})$, and brefeldin A $(5 \mu \mathrm{g} / \mathrm{ml})$ (Enzo, Lörrach, Germany) at $37^{\circ} \mathrm{C}$ for $5 \mathrm{~h}$. After stimulation, cells were 
washed with PBS. Mouse cells were then stained with anti-mouse CD4 for $30 \mathrm{~min}$ on ice, washed with PBS, and finally stained with intracellular cytokines (anti-mouse IFN- $\gamma$, IL-4, or IL-17A) for 30 min using a Fixation/Permeabilization Kit (Nordic-MUbio, Susteren, The Netherlands). Human cells were then stained with anti-human linage cocktail and anti-human HLA-DR for 30 min on ice, washed with PBS, and stained with anti-human IL-12p40 using the same Fixation/ Permeabilization Kit. Unstimulated mouse splenocytes were stained for detection of Tfh and Treg cells. For detection of Treg cells, cells were first stained with anti-mouse CD4 for $30 \mathrm{~min}$ on ice, washed with PBS, permeated by a Foxp3 staining buffer (ebioscience, San Diego, CA) for $1 \mathrm{~h}$, washed with PBS, and stained with anti-mouse Foxp3 for 30 min. For staining of Tfh cells, splenocytes were stained with anti-mouse CD4, CXCR5, and PD-1 for $30 \mathrm{~min}$ on ice. Data were acquired using a FACS calibur system (BD Biosciences, San Jose, CA) and analyzed by FlowJo software. All antibodies were purchased from Miltenyi Biotec (Bergisch Gladbach, Germany) or eBioscience (San Diego, CA, USA).

\section{Cytokine detection}

After collection of whole blood from SS patients and healthy controls, samples were immediately centrifuged at $1400 \mathrm{~g}$ for isolation of serum; serum was then subpackaged and stored at $-80{ }^{\circ} \mathrm{C}$ to avoid repeated freeze/ thaw cycles. All samples were brought to room temperature before cytokine detection. Levels of serum IL-12 in SS patients and healthy controls were detected by enzyme-linked immunosorbent assay (ELISA) (R\&D systems, D1200). The experiments were performed according to the manufacturer's instructions. For measurement of IL-12 levels in SS patients or NOD mice before and after MSCT, luminex chips assay (Merck\&Millipore, MA, USA) was used.

\section{Human and mouse DC preparation}

For generating human monocyte-derived DCs, peripheral blood mononuclear cells (PBMCs) were isolated from healthy subjects by Ficoll-Paque density gradient centrifugation. CD14+ monocytes were isolated by magnetic cell sorting kit (Miltenyi, 130-097-052) according to the manufacturer's instructions. Purified CD14+ cells were cultured in 24-well plate in complete RPMI-1640 media and stimulated with $100 \mathrm{ng} / \mathrm{ml}$ granulocytemacrophage colony-stimulating factor (GM-CSF) plus $100 \mathrm{ng} / \mathrm{ml} \mathrm{IL-4}$ for 5 days for induction of immature DCs. Subsequently, $100 \mathrm{ng} / \mathrm{ml}$ lipopolysaccharides (LPS) was added to induce DC maturation. Forty-eight hours later, the cells were used as human monocyte-derived DCs. CD11c+ cells were isolated from splenocytes by magnetic cell sorting kit (Miltenyi, 130-097,059) and used as mouse DCs.

\section{UCMSC-DC co-culture experiments}

DCs were prepared as described above. We used monocyte-derived DCs generated from $\mathrm{HC}$ subjects and $\mathrm{CD} 11 \mathrm{c}+\mathrm{DCs}$ from C57BL/6 mice in the co-culture experiments. A trans-well system (Corning, Corning, NY, USA) was used to perform the co-culture experiments. DCs were plated in the lower chamber. UCMSCs of passages 3-5 were seeded into the trans-well membrane of the inner chamber with $0.4-\mu \mathrm{m}$ pore size prior to the co-culture experiment to allow adherence overnight; cells were cultivated in complete RPMI 1640 medium. The ratio of UCMSCs to DCs was 1:5. Forty-eight hours after co-culture, cells were harvested for conducting further experiments.

\section{RNA isolation and real-time polymerase chain reaction (RT-PCR)}

Total RNA samples were extracted from human or mouse DCs. Complementary DNA (cDNA) was synthesized by PrimeScript RT regent kit (Takara Biotechnology, Tokyo, Japan). Real-time PCR was performed to detect IL-12 mRNA levels on an Applied Biosystems 7500 real-time PCR system (Applied Biosystems, Foster City, USA). Data analysis was performed using an SDS software (version 2.0, Applied Biosystems). Primers were designed and synthesized by Takara Biotechnology. The relative expressions of each gene were determined and normalized to the expression of housekeeping gene glyceraldehyde 3-phosphate dehydrogenase (GAPDH) and calculated using the $2^{-\triangle \Delta C T}$ method. Primer sequences were listed in Additional file 1: Table S2.

\section{Histologic analysis}

After mice were sacrificed, submandibular glands (SGs) were collected and immediately fixed in $4 \%$ paraformaldehyde. Paraformaldehyde-fixed tissues were embedded in paraffin. Serial $4-\mu \mathrm{m}$ sections were cut and stained with hematoxylin and eosin (H\&E) for morphologic examination. Chisholm-Mason classification criteria were applied to define lymphocyte infiltrations in SGs [27].

\section{Statistical analysis}

Data was presented as mean $\pm \mathrm{SD}$ in each group. All statistical analyses were performed using GraphPad Prism 6 software (GraphPad Software, La Jolla, CA, USA). Spearman's test was carried out to analyze correlations of IL-12 levels with ESSDAI scores. Statistical significances were determined by one-way ANOVA. When only two groups were analyzed, paired or 
unpaired Student $t$ test was used. A $p$ value $<0.05$ was considered significant difference.

\section{Results}

Increased IL-12 in SS patients positively correlates with disease activity

To explore the differential expression levels of IL-12 in SS patients and $\mathrm{HC}$ subjects, we measured serum IL-12 levels by ELISA. Figure 1a shows that serum IL-12 levels were significantly increased in SS patients $(p<0.05)$. As dendritic cells were the main producer of IL-12 in vivo, we then detected IL-12 expression in DCs. Figure $1 \mathrm{~b}$ shows that the in vitro generated monocyte-derived DCs from SS patients expressed higher IL-12 mRNA levels $(p<0.05)$. Besides, flow cytometry analysis also showed higher IL-12 expression levels in Lin-HLA-DR+ subgroups (which represent DCs) in SS VS HC PBMCs $(p<0.001)$. This data suggested that elevated IL-12 might be related to SS pathogenesis. In order to detect the possible relationship, we scored the ESSDAI of SS patients and performed correlation analysis of ESSDAI scores with IL-12 levels by Spearman's test. Figure $1 \mathrm{~d}$ shows that IL-12 levels positively correlated with ESSDAI scores $\left(p<0.05, R^{2}=0.1416\right)$. Lymphocyte infiltrations in SGs of SS patients were determined by ChisholmMason grade. Of 29 SG biopsy slides, 4 had a Chisholm-
Mason grade $<$ I and 25 had a grade $\geq$ I, and serum IL-12 levels were significantly higher in the latter group $(p<0.05$, Fig. 1e), suggesting that IL-12 might accelerate lymphocyte infiltrations into SGs in SS patients. However, IL-12 levels did not correlate with SSA or SSB antibodies in the SS patients (Additional file 1: Figure S1).

\section{MSC transplantation ameliorates SS-like symptoms in NOD mice}

To examine the therapeutic effects of MSCs in NOD mice, we injected $1 \times 10^{6}$ MSCs via tail vein into the mice, with same numbers of FLS or same volume of sterilized PBS as controls. Our results showed a significant improvement of saliva flow rate in the MSC-treated group compared to untreated NOD mice $(p<0.05$, Fig. 2a). The lymphocytic infiltration in the submandibular glands was decreased in this MSC-treated group (Fig. 2b). The data suggested that MSCs had beneficial roles in improving the salivary gland functions in NOD mice.

\section{MSC transplantation regulates $\mathrm{T}$ cell responses in NOD mice}

It was reported that $\mathrm{T}$ cell responses, in particular Th17 cells, play critical roles in human pSS and in SS animal models $[26,28]$. So we next examined the effects of

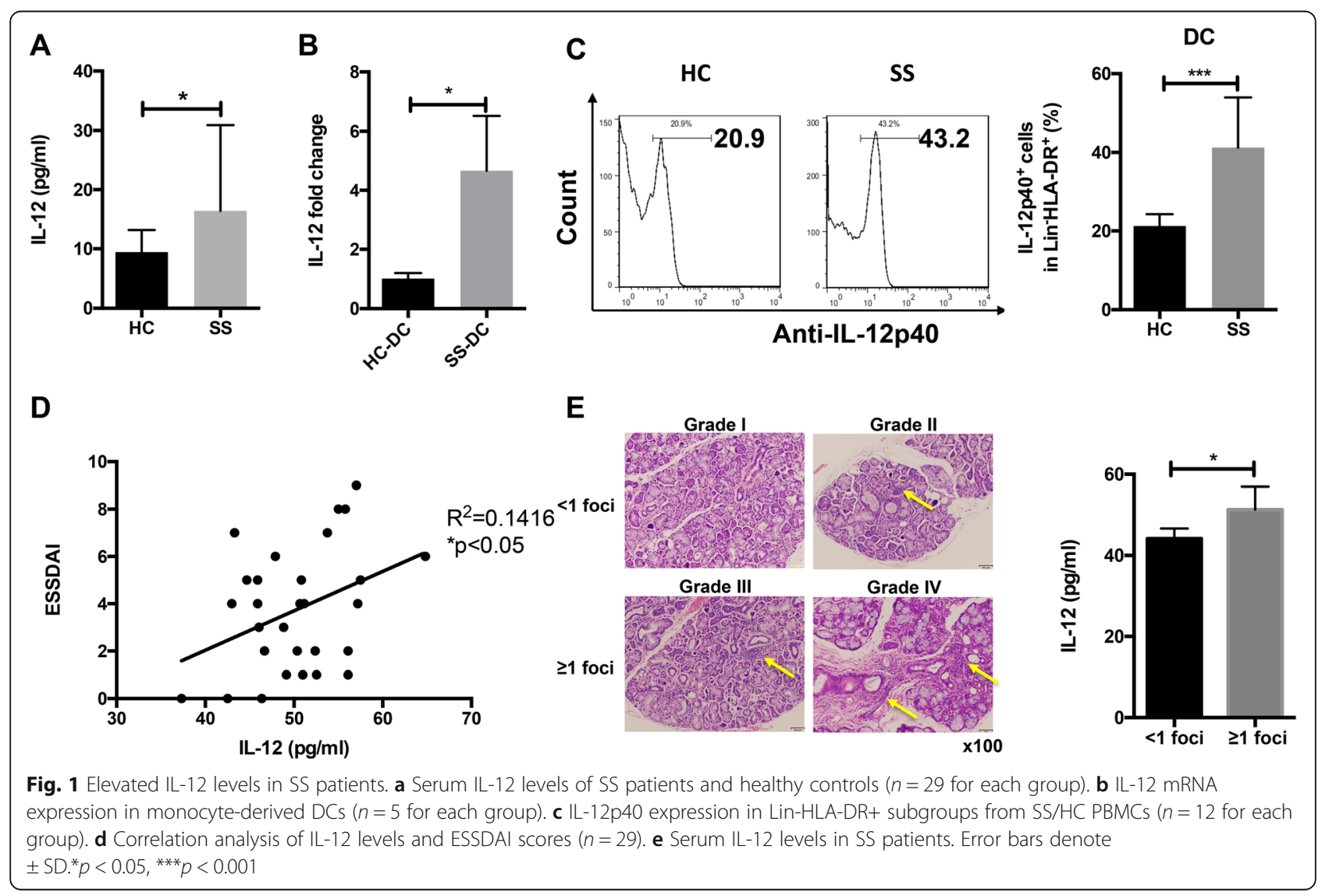




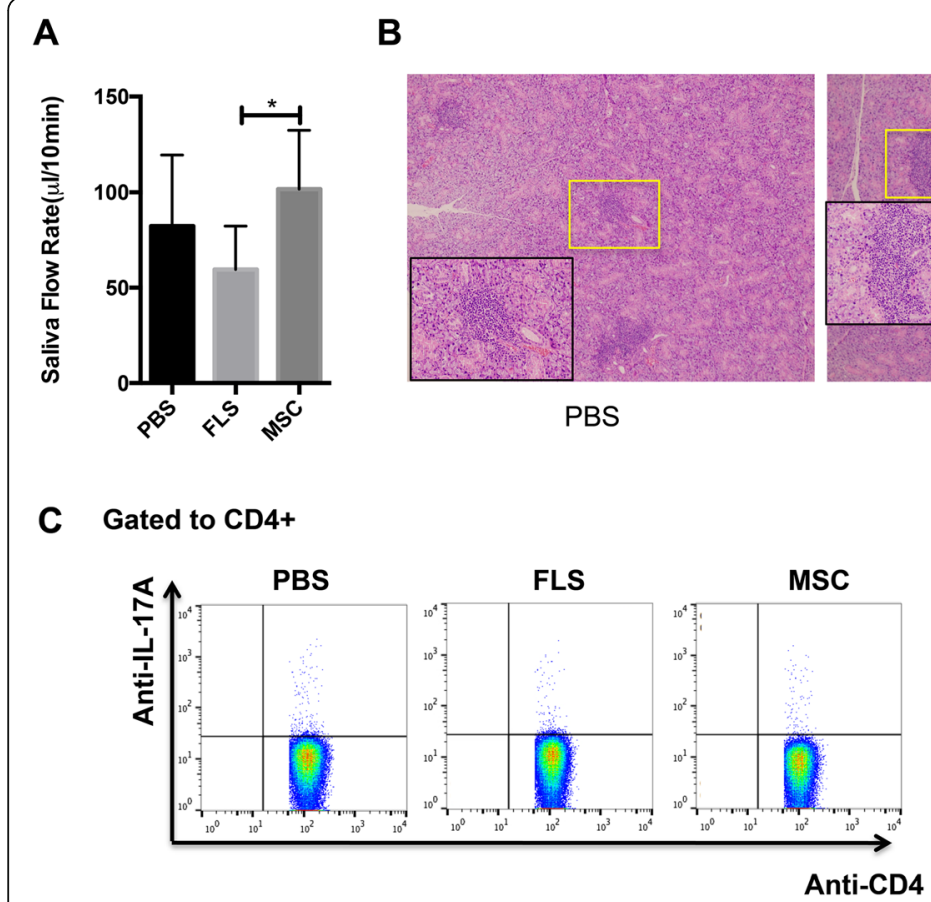

D Gated to CD4+
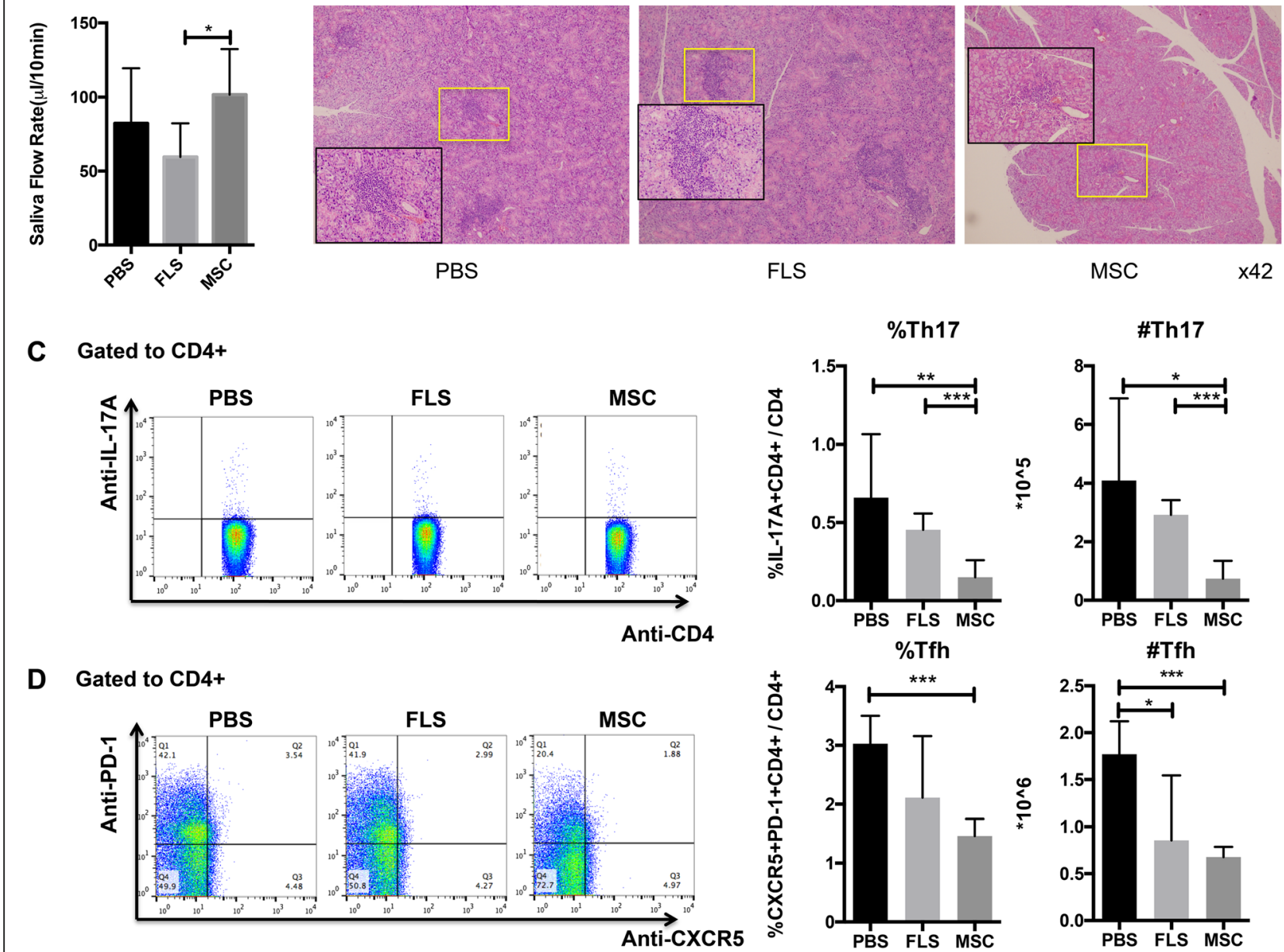

FLS

\#Th17
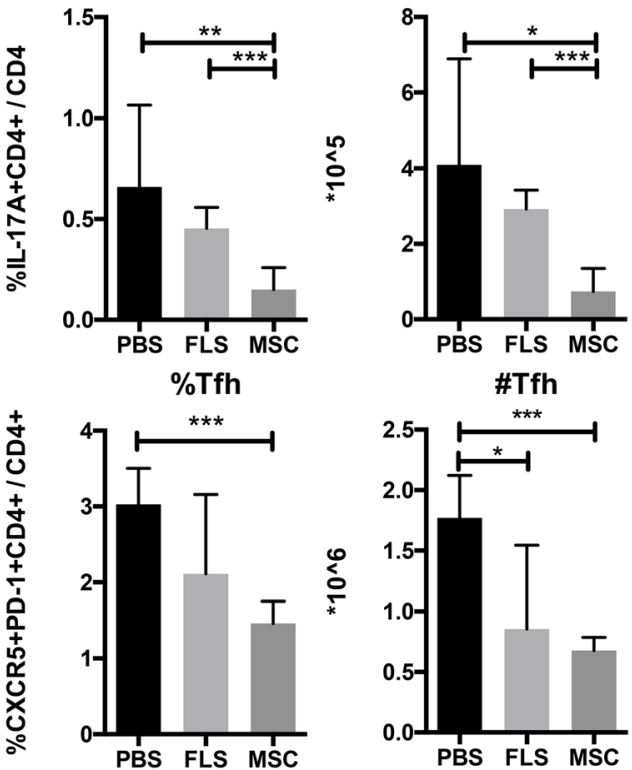

\#Tfh

\section{E Gated to CD4+}
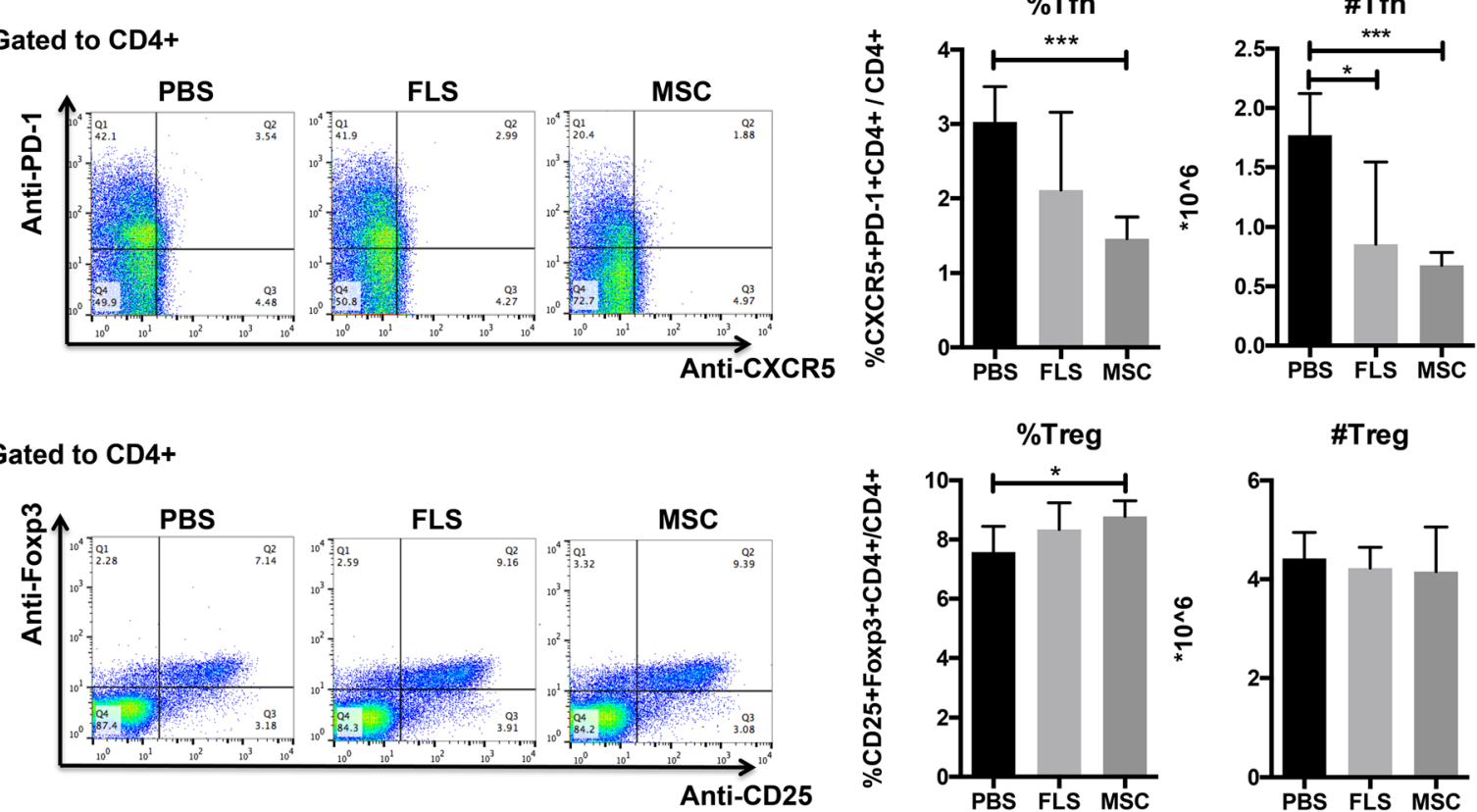

\#Treg

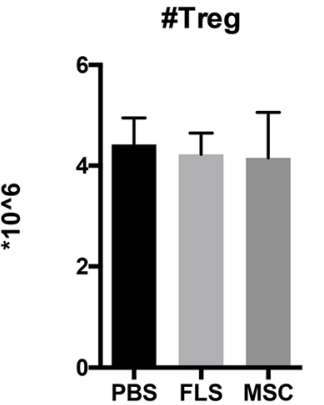

Fig. 2 MSCT improved SFRs in NOD mice, ameliorated lymphocytic infiltrations in submandibular glands, and regulated T cell responses. a Saliva flow rate of mice at day 28 after MSC/FLS/PBS treatment ( $n=5$ for each group). $\mathbf{b}$ Histopathology of submandibular glands determined by HE staining ( $n=5$ for each group). c-e Percentages and absolute numbers of Th17 (CD4+IL-17+), Tfh (CD4+CXCR5+PD-1+), and Treg (CD4+CD25 + Foxp3+) cells in splenocytes of mice ( $n=5$ for each group). Data were analyzed by one-way ANOVA. Error bars denote \pm SD. ${ }^{*} p<0.05$, ${ }^{* *} p<0.01,{ }^{* * *} p<0.001$

MSCT on lymphocyte subsets of the NOD mice. MSC transplantation reduced the percentages and absolute numbers of Th17 $(p<0.05$, Fig. 2c) and Tfh cells $(p<$ 0.05 , Fig. 2d), whereas upregulated Treg cells in the spleens $(p<0.05$, Fig. 2e). However, it had no influence on plasma cells (PC), Th1 and Th2 cells (Additional file 1:
Figure S2A-C). These results further supported the effectiveness of MSCT in treating SS.

MSCs inhibit IL-12 production in DCs

Next, we detected whether IL-12 levels decrease in parallel with MSCT. In the 10 SS patients enrolled, we 


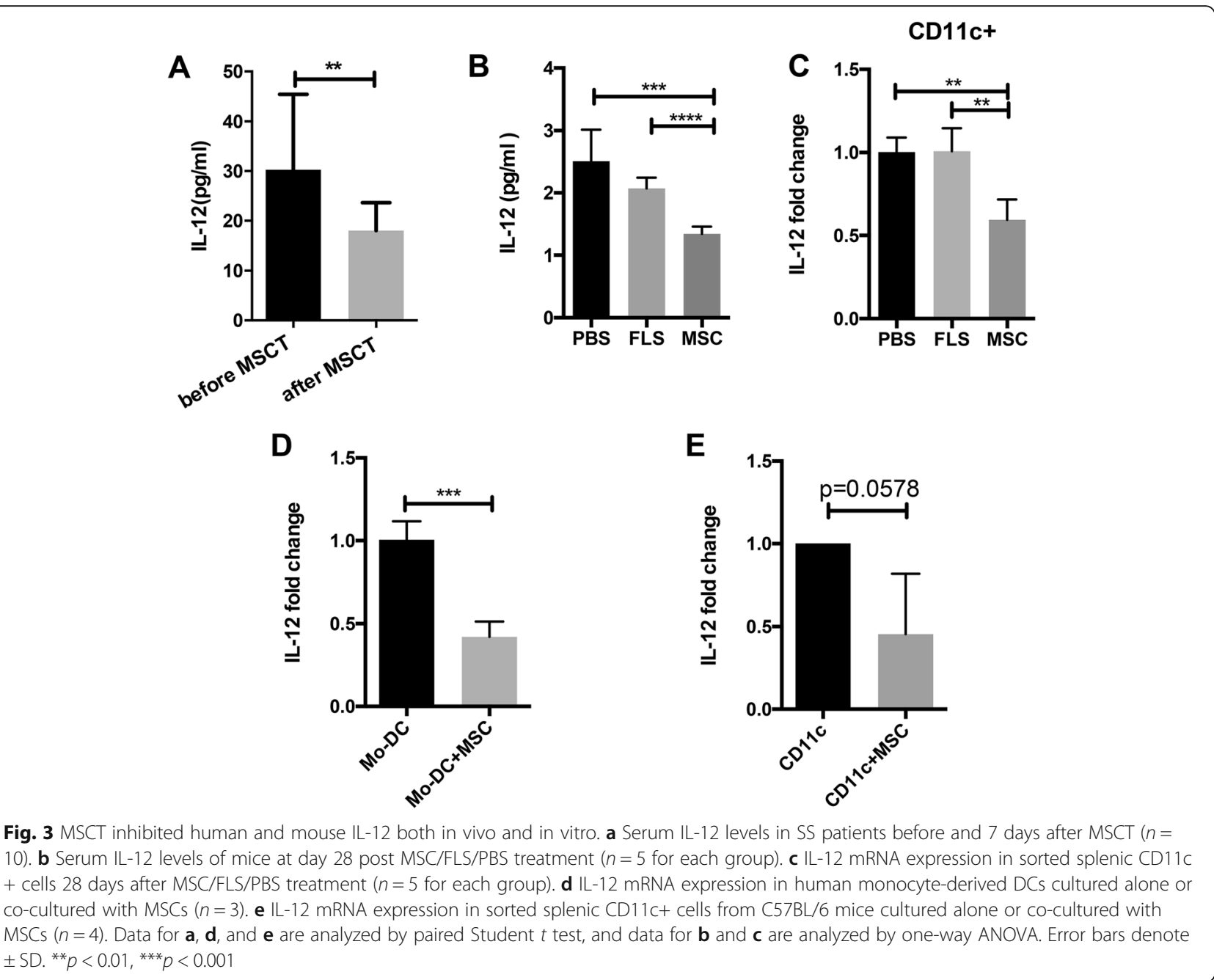

found a significant decrease of serum IL-12 levels 7 days after MSCT $(p<0.01$, Fig. 3a). We then examined IL-12 changes in NOD mice with MSCT or FLS/PBS as controls. We found that 28 days after the treatment, serum IL-12 levels were significantly decreased in the MSCT group $(p<0.001$, Fig. $3 \mathrm{~b})$. Then, we detected IL-12 mRNA expression in the sorted CD11c+ DCs. Notably, CD11c+ DCs in the MSCT group expressed significantly lower levels of IL-12 $(p<0.01$, Fig. 3c). These data suggest MSCs could inhibit IL-12 productions in vivo, both in the SS patients and mice. We then detected whether MSCs could inhibit IL-12 production in DCs in vitro. Monocyte-derived DCs were used as human DCs; after the co-culture experiment, we found significant inhibited IL-12 expression in the DCs with MSC treatment $(p<0.001$, Fig. $3 \mathrm{~d})$. CD11c+ cells from splenocytes of C57BL/6 mice were used to present mouse DCs; not surprisingly, inhibited IL-12 production was also observed in mouse DCs co-cultured with MSCs $(p=0.05$, Fig. 3e). These results further supported the findings that MSCs inhibited IL-12 in vivo.
IL-12 treatment exacerbates disease activity in NOD mice We next examined whether in vivo administration of IL-12 or IL-12 antibody could influence the disease progression of NOD mice. Saliva flow rates were comparable between the IL-12 antibody and PBS treatment group (Fig. 4a), although we found milder inflammatory infiltrates in the submandibular glands of IL-12 antibody-treated mice (Fig. 4b). IL-12 antibodies also decreased percentages and absolute numbers of Th1 $(p<$ 0.05 , Fig. 4c), Th17 cells $(p<0.01$, Fig. 4 d), and Tfh cells $(p<0.001$, Fig. 4e). No significant differences were found in percentages or numbers of Th2, Treg, and plasma cells (Additional file 1: Figure S3). Collectively, these data demonstrate that IL-12 antibody plays beneficial roles in inhibiting Th1, Th17, and Tfh cells, which were previously reported to be increased in SS patients [26]. On the other hand, recombinant IL-12 significantly decreased salivary flow rates and strongly induced lymphocytic infiltration foci in the submandibular glands, while had weak influence on lymphocyte subsets in the spleen (Additional file 1: Figure S4). 

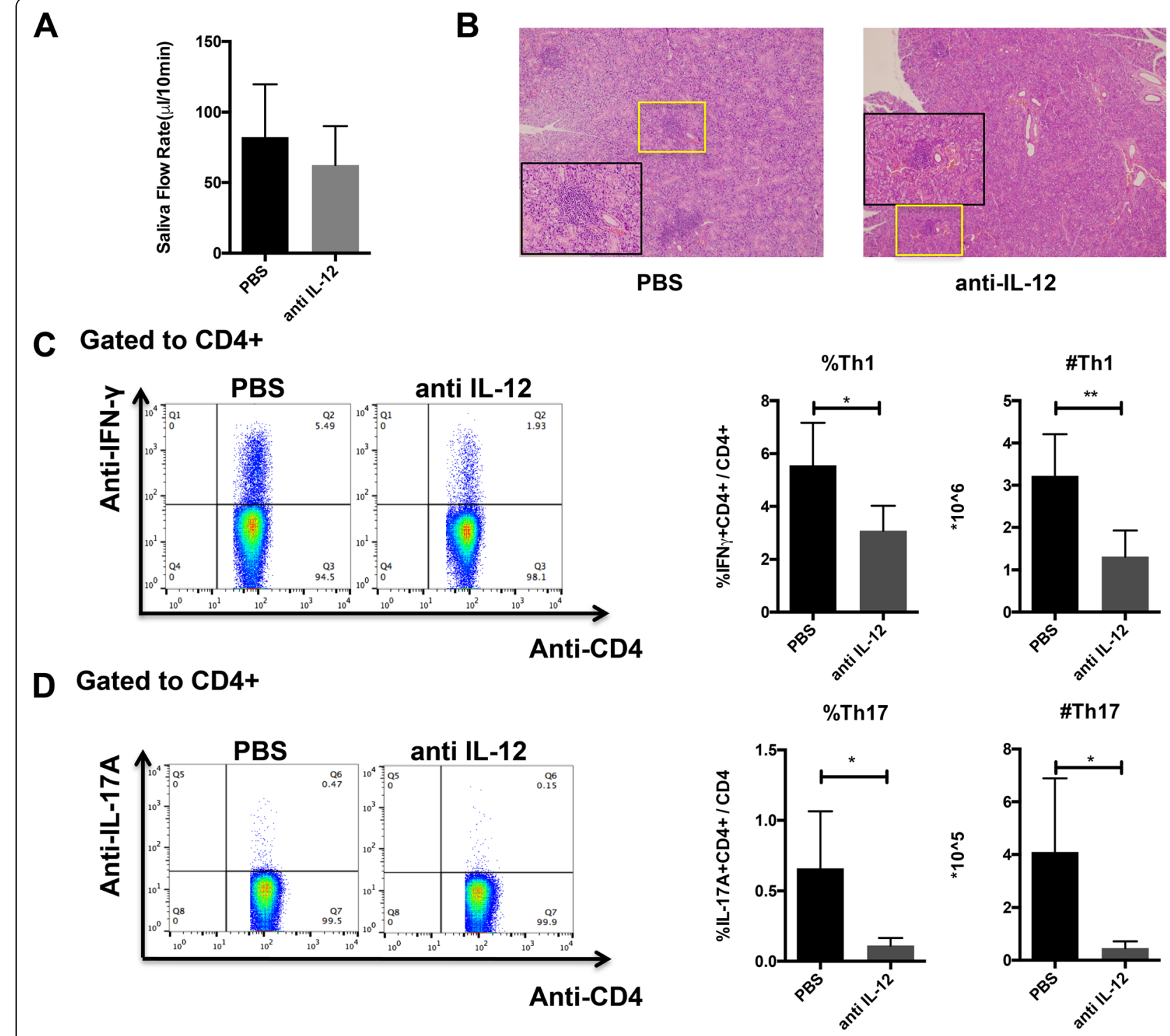

\section{E Gated to CD4+}
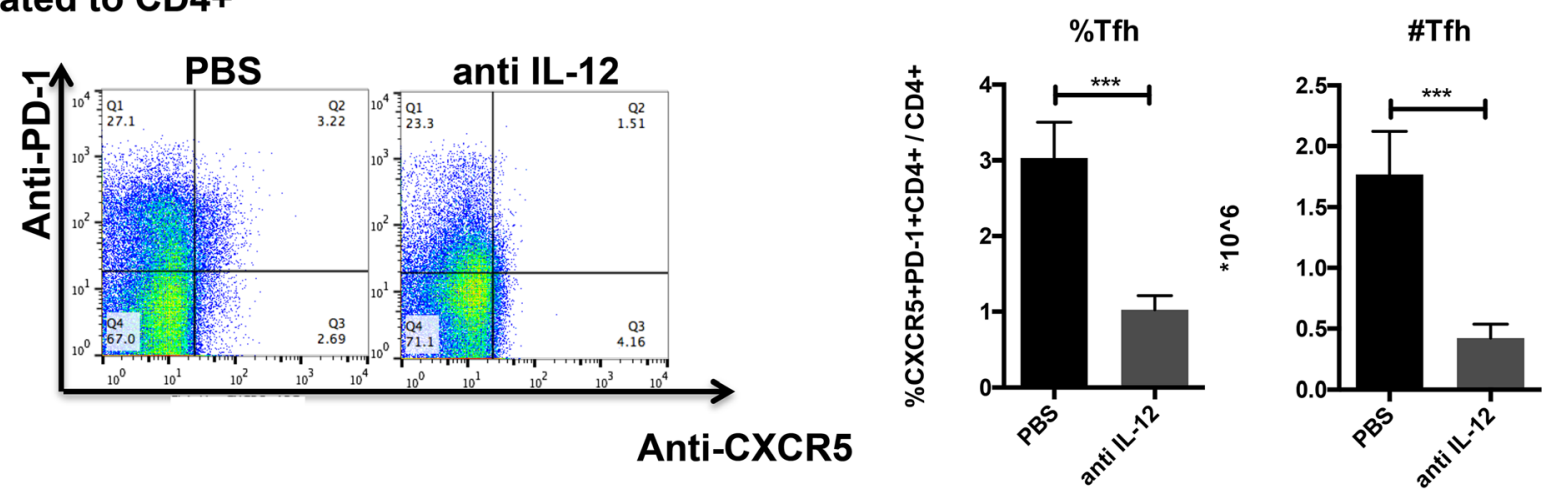

Fig. 4 IL-12 antibodies ameliorated SS-like symptoms in NOD mice partially by regulating T cell responses. a Saliva flow rates of mice on day 7 after treatment with PBS or IL-12 antibody ( $n=5$ for each group). b Histopathology of submandibular glands determined by HE staining ( $n=5$ for each group). c-e Percentages and absolute numbers of Th1 (CD4+IFN- $\gamma$ ), Th17 (CD4+IL-17+), and Tfh (CD4+CXCR5+PD-1+) cells in splenocytes of mice ( $n=5$ for each group). Data are analyzed by unpaired Student $t$ test. Error bars denote \pm SD. ${ }^{*} p<0.05,{ }^{* *} p<0.01,{ }^{* *} p<0.001$ 


\section{Discussion}

IL-12 had been reported to be increased in several autoimmune diseases. It was elevated in patients with RA and decreased after the patients were treated with disease-modifying anti-rheumatic drugs (DMARD) [29, 30]. Antibodies against IL-12/23 have been proven to be effective in alleviating autoimmune diseases including rheumatoid arthritis, psoriasis, and multiple sclerosis [29, 31, 32].

The role of IL-12 in SS pathogenesis is controversial. Lode et al. reported an increased expression of IL-12 in submandibular glands with severe inflammatory infiltrates in NOD mice, and Ohyama et al. reported higher IL-12 expression in the labial salivary glands of some SS patients [33, 34]. In contrast, Szodory et al. revealed decreased IL-12 levels in SS patients, and in those with extra-exocrine manifestations, IL-12 levels were much lower than those who only suffer from exocrine gland destructions [35]. Here, we demonstrate that IL-12 levels were elevated in SS patients and correlated with disease activity index; our results suggest that IL-12 promoted SS pathogenesis. The reasons for the difference between our and Szodory et al.'s results remain to be further clarified, which at this moment we thought might be attributed to the heterogeneity of the SS patients enrolled. In addition, we did not assort the patients according to the presence or absence of extra-exocrine manifestations, which might be another variant of the results interpreted.

MSCs are multipotent stem cells with strong immune-regulatory functions [36]. MSCs possess immune-regulatory effects on various immune cells like T cells, B cells, DCs, and macrophages [37-40]. MSCs regulate DCs in many aspects. First, MSCs inhibit differentiation of DCs from their precursors, both from monocytes and from CD34+ cells, and this was suggested to be regulated by inhibited cyclin D1 in monocytes and CD1a expression on DCs $[41,42]$. MSCs also impair differentiated DCs to express CD80, CD86, CD40, and CD83, which present mature DC phenotype [43]. Moreover, DCs generated in the presence of MSCs were functionally impaired [20]. As IL-12 was mainly produced by activated APCs, especially DCs, we suggest that the inhibition of MSCs on IL-12 might be attributed to the impairment of both DC differentiation and maturation processes.

MSCs lack the expression of co-stimulatory molecules and display low immunogenicity, which make them incapable of alloantigen recognition. Owing to these immunologic features, MSCs have been used in the clinical treatment of autoimmune diseases. Published studies had demonstrated the effectiveness and safety of MSCT for autoimmune disease (AD) [44-46]. We hypothesized that MSCs were effective in treating AD at least in part by regulating cytokine production and the balance of lymphocyte subsets. Indeed, we revealed that MSCs improved the Th17/Treg balance in NOD mice, and inhibited Tfh cells. In addition, we found that IL-12 played a key role in SS partially by inducing saliva loss and regulating $\mathrm{T}$ cell responses. Importantly, we uncovered that MSCT reduced IL-12 levels both in patients and animal models, revealing a previously unrecognized mechanism underlying MSC treatment-mediated improvement of Sjögren's syndrome. However, the molecular mechanisms of how MSCs regulate IL-12 production were not detected in this study, which deserves future investigations.

\section{Conclusions}

In this article, we report that elevated serum IL-12 levels in SS patients correlate positively with disease activity. MSCT ameliorates SS-like symptoms in NOD mice and inhibited human and mouse IL-12 both in vivo and in vitro. Our findings indicate that MSCs ameliorate SS possibly via suppressing IL-12 production and that IL-12 could be a potential therapeutic target of SS.

\section{Additional file}

\begin{abstract}
Additional file 1: Table S1. Clinical features of SS patients treated with MSCT. Table S2. Primer sequences for real-time PCR. Figure S1. IL-12 levels did not correlate with SSA or SSB antibodies. Figure S2. A: No inflammatory infiltrates into lacrimal glands in any of the three groups. B-D: MSCT had modest influence on plasma cells (PC), Th1 and Th2 cells. Figure S3. No significant differences were found in percentages or numbers of Th2, Treg and plasma cells in the anti-IL-12 treatment group. Figure S4. IL-12 significantly reduced saliva flow rates and induced lymphocytic infiltrates into submandibular glands in NOD mice, while had modest influence on PC, Th1, Th2, Th17, Treg and Tfh cell subsets in the spleen. (DOCX $1767 \mathrm{~kb}$ )
\end{abstract}

\section{Abbreviations}

AD: Autoimmune disease; ADMSCs: Adipose tissue mesenchymal stem cells; BMMSCs: Bone marrow mesenchymal stem cells; cDNA: Complementary DNA; DCs: Dendritic cells; DMARD: Disease-modifying anti-rheumatic drugs; ELISA: Enzyme-linked immunosorbent assay; ESSDAI: EULAR 2010 Sjögren's syndrome disease activity index; FLS: Fibroblast-like cells; GMCSF: Granulocyte-macrophage colony-stimulating factor; HC: Healthy controls; IBD: Inflammatory bowel disease; IL: Interleukin;

LPS: Lipopolysaccharides; MSCs: Mesenchymal stem cells; MSCT: MSC transplantation; NOD: Non-obese diabetic; PBMCs: Peripheral blood mononuclear cells; PBS: Phosphate-buffered saline; PGE2: Prostaglandin E2; PMA: Phorbol 12-myristate 13-acetate; RA: Rheumatoid arthritis; SG: Salivary glands; SLE: Systemic lupus erythematosus; SS: Sjögren's syndrome; UCMSCs: Umbilical cord mesenchymal stem cells

\section{Acknowledgements}

The authors acknowledge the financial support by the Affiliated Drum Tower Hospital of Nanjing University and the National Natural Science Foundation of China.

\section{Funding}

This work was supported by the National Natural Science Foundation of China (NSFC) (grant no. 81571583 and 81770061 to GY). The study was supported by the Major International (Regional) Joint Research Project (grant no. 81720108020 to LS), Jiangsu Province Major Research and Development Program (grant no. BE2015602 to LS) and China National Natural Science Foundation (grant no. 91442119 to LS). 


\section{Availability of data and materials}

The data that support the findings of this study are available from the corresponding author or first author upon reasonable request.

\section{Authors' contributions}

All authors were involved in drafting and revising the article, and all authors approved the final version to be published. BS, GY, and LS conceived and planned the study and drafted the manuscript. BS, JQ, RF, ZZ, and CC performed the experiments. BS, DW, LL, and LS were responsible for the analysis and interpretation of data. LS and WC supervised the study and edited the manuscript. All authors approved the final manuscript.

\section{Ethics approval and consent to participate}

All animal experiments were approved by Ethics Committee of the Affiliated Drum Tower Hospital of Nanjing University Medical School. This study was approved by the Ethics Committee at the Drum Tower Hospital of Nanjing University Medical School and registered at http://www.clinicaltrials.gov. (NTC00953485, Allogeneic Mesenchymal Stem Cells Transplantation for Primary Sjögren's Syndrome, registered August 6, 2009, first participant enrolled on September 1, 2009). All patients gave consent to participate.

\section{Consent for publication}

Not applicable.

\section{Competing interests}

The authors declare that they have no competing interests.

\section{Publisher's Note}

Springer Nature remains neutral with regard to jurisdictional claims in published maps and institutional affiliations.

\section{Author details}

'Department of Rheumatology and Immunology, The Affiliated Drum Tower Hospital of Nanjing University Medical School, Nanjing, China. ${ }^{2}$ Department of Pathology and Center of Infection and Immunology, University of Hong Kong, Hong Kong, China. ${ }^{3}$ National Institute of Dental and Craniofacial Research, NIH, Bethesda, MD, USA.

\section{Received: 3 April 2018 Revised: 1 September 2018}

Accepted: 30 September 2018 Published online: 08 November 2018

\section{References}

1. Liang J, Li X, Zhang H, Wang D, Feng X, Wang $H$, et al. Allogeneic mesenchymal stem cells transplantation in patients with refractory RA. Clin Rheumatol. 2012;31(1):157-61. https://doi.org/10.1007/s10067-011-1816-0.

2. Liang J, Zhang $H$, Wang D, Feng $X$, Wang $H$, Hua B, et al. Allogeneic mesenchymal stem cell transplantation in seven patients with refractory inflammatory bowel disease. Gut. 2012;61(3):468-9. https://doi.org/10.1136/ gutjil-2011-300083.

3. Uccelli A, Moretta L, Pistoia V. Mesenchymal stem cells in health and disease. Nat Rev Immunol. 2008;8(9):726-36. https://doi.org/10.1038/nri2395.

4. Yagi H, Soto-Gutierrez A, Parekkadan B, Kitagawa Y, Tompkins RG, Kobayashi $\mathrm{N}$, et al. Mesenchymal stem cells: mechanisms of immunomodulation and homing. Cell Transplant. 2010;19(6-7):667-79. https://doi.org/10.3727/ $096368910 \times 508762$

5. Lim J-Y, Yi T, Choi J-S, Jang YH, Lee S, Kim HJ, et al. Intraglandular transplantation of bone marrow-derived clonal mesenchymal stem cells for amelioration of post-irradiation salivary gland damage. Oral Oncol. 2013; 49(2):136-43. https://doi.org/10.1016/.oraloncology.2012.08.010.

6. Kojima, T., S. Kanemaru, S. Hirano, I. Tateya, S. Ohno, T. Nakamura, et al:: Regeneration of radiation damaged salivary glands with adipose-derived stromal cells. Laryngoscope 2011; 121(9):1864-9. doi:https://doi.org/10.1002/lary.22080

7. Khalili S, Liu YN, Kornete M, Roescher N, Kodama S, Peterson A, et al. Mesenchymal stromal cells improve salivary function and reduce lymphocytic infiltrates in mice with Sjogren's-like disease. PLoS One. 2012; 7(6):11. https://doi.org/10.1371/journal.pone.0038615.

8. Xu J, Wang D, Liu D, Fan Z, Zhang H, Liu O, et al. Allogeneic mesenchyma stem cell treatment alleviates experimental and clinical Sjogren syndrome. Blood. 2012;120(15):3142-51. https://doi.org/10.1182/blood-2011-11-391144.

9. Trinchieri G. Interleukin-12 and the regulation of innate resistance and adaptive immunity. Nat Rev Immunol. 2003;3(2):133-46. https://doi.org/10.1038/nri1001.
10. Vosters JL, Landek-Salgado MA, Yin H, Swaim WD, Kimura H, Tak PP, et al. Interleukin-12 induces salivary gland dysfunction in transgenic mice, providing a new model of Sjogren's syndrome. Arthritis Rheum. 2009;60(12): 3633-41. https://doi.org/10.1002/art.24980.

11. Delaleu N, Immervoll H, Cornelius J, Jonsson R. Biomarker profiles in serum and saliva of experimental Sjogren's syndrome: associations with specific autoimmune manifestations. Arthritis Res Ther. 2008;10(1):R22. https://doi.org/10.1186/ar2375.

12. Gottenberg JE, Lavie F, Abbed K, Gasnault J, Le Nevot E, Delfraissy JF, et al. CD4 CD25high regulatory $T$ cells are not impaired in patients with primary Sjogren's syndrome. J Autoimmun. 2005;24(3):235-42. https://doi.org/10. 1016/j.jaut.2005.01.015.

13. Katsifis GE, Moutsopoulos NM, Wahl SM. T lymphocytes in Sjogren's syndrome: contributors to and regulators of pathophysiology. Clin Rev Allergy Immunol. 2007;32(3):252-64. https://doi.org/10.1007/s1 2016-007-8011-8.

14. Liu R, Su D, Zhou M, Feng X, Li X, Sun L. Umbilical cord mesenchymal stem cells inhibit the differentiation of circulating $T$ follicular helper cells in patients with primary Sjogren's syndrome through the secretion of indoleamine 2,3-dioxygenase. Rheumatology (Oxford). 2015;54(2):332-42. https://doi.org/10.1093/rheumatology/keu316.

15. Bifari F, Lisi V, Mimiola E, Pasini A, Krampera M. Immune modulation by mesenchymal stem cells. Transfus Med Hemother. 2008;35(3):194-204. https://doi.org/10.1159/000128968.

16. Bacskai I, Mazlo A, Kis-Toth K, Szabo A, Panyi G, Sarkadi B, et al. Mesenchymal stromal cell-like cells set the balance of stimulatory and inhibitory signals in monocyte-derived dendritic cells. Stem Cells Dev. 2015; 24(15):1805-16. https://doi.org/10.1089/scd.2014.0509.

17. Jung YJ, Ju SY, Yoo ES, Cho SJ, Cho KA, Woo Y, et al. MSC-DC interactions: MSC inhibit maturation and migration of BM-derived DC. Cytotherapy. 2007; 9(5):451-8. https://doi.org/10.1080/14653240701452057.

18. Deng W, Chen WW, Zhang ZY, Huang SS, Kong W, Sun Y, et al. Mesenchymal stem cells promote CD206 expression and phagocytic activity of macrophages through IL-6 in systemic lupus erythematosus. Clin Immunol. 2015;161(2):209-16. https://doi.org/10. 1016/j.clim.2015.07.011.

19. Dayan V, Yannarelli G, Billia F, Filomeno P, Wang XH, Davies JE, et al. Mesenchymal stromal cells mediate a switch to alternatively activated monocytes/macrophages after acute myocardial infarction. Basic Res Cardiol. 2011;106(6):1299-310. https://doi.org/10.1007/s00395-011-0221-9.

20. Spaggiari GM, Abdelrazik H, Becchetti F, Moretta L. MSCs inhibit monocyte-derived DC maturation and function by selectively interfering with the generation of immature DCs: central role of MSC-derived prostaglandin E(2). Blood. 2009;113(26):6576-83. https://doi.org/10.1182/ blood-2009-02-203943.

21. Wheat WH, Chow L, Kurihara JN, Regan DP, Coy JW, Webb TL, et al. Suppression of canine dendritic cell activation/maturation and inflammatory cytokine release by mesenchymal stem cells occurs through multiple distinct biochemical pathways. Stem Cells Dev. 2017;26(4):249-62. https:// doi.org/10.1089/scd.2016.0199.

22. Wang $\mathrm{D}$, Feng $X, L u L$, Konkel JE, Zhang $H$, Chen Z, et al. A CD8 T cell/ indoleamine 2,3-dioxygenase axis is required for mesenchymal stem cell suppression of human systemic lupus erythematosus. Arthritis Rheumatol. 2014;66(8):2234-45. https://doi.org/10.1002/art.38674.

23. Reisch N, Engler A, Aeschlimann A, Simmen BR, Michel BA, Gay RE, et al. DREAM is reduced in synovial fibroblasts of patients with chronic arthritic pain: is it a suitable target for peripheral pain management? Arthritis Res Ther. 2008;10(3):R60. https://doi.org/10.1186/ar2431.

24. Vitali C, Bombardieri S, Jonsson R, Moutsopoulos HM, Alexander EL, Carsons $\mathrm{SE}$, et al. Classification criteria for Sjogren's syndrome: a revised version of the European criteria proposed by the American-European Consensus Group. Ann Rheum Dis. 2002;61(6):554-8.

25. Seror R, Ravaud P, Bowman SJ, Baron G, Tzioufas A, Theander E, et al. EULAR Sjogren's syndrome disease activity index: development of a consensus systemic disease activity index for primary Sjogren's syndrome. Ann Rheum Dis. 2010;69(6):1103-9. https://doi.org/10.1136/ard.2009.110619.

26. Lin X, Rui K, Deng J, Tian J, Wang X, Wang S, et al. Th17 cells play a critical role in the development of experimental Sjogren's syndrome. Ann Rheum Dis. 2015;74(6):1302-10. https://doi.org/10.1136/annrheumdis-2013-204584.

27. Chisholm DM, Mason DK. Labial salivary gland biopsy in Sjogren's disease. J Clin Pathol. 1968;21(5):656-60.

28. Katsifis GE, Rekka S, Moutsopoulos NM, Pillemer S, Wahl SM. Systemic and local interleukin-17 and linked cytokines associated with Sjogren's syndrome 
immunopathogenesis. Am J Pathol. 2009;175(3):1167-77. https://doi.org/10. 2353/ajpath.2009.090319.

29. Petrovic-Rackov L, Pejnovic N. Clinical significance of IL-18, IL-15, IL-12 and TNF-alpha measurement in rheumatoid arthritis. Clin Rheumatol. 2006;25(4): 448-52. https://doi.org/10.1007/s10067-005-0106-0.

30. Kim WU, Min SY, Cho ML, Youn J, Min JK, Lee SH, et al. The role of IL-12 in inflammatory activity of patients with rheumatoid arthritis (RA). Clin Exp Immunol. 2000;119(1):175-81. https://doi.org/10.1046/.1365-2249.2000.01095.x.

31. Comabella M, Balashov K, Issazadeh S, Smith D, Weiner HL, Khoury SJ. Elevated interleukin-12 in progressive multiple sclerosis correlates with disease activity and is normalized by pulse cyclophosphamide therapy. J Clin Investig. 102(4):671-8. https://doi.org/10.1172/JCl3125.

32. Teng MW, Bowman EP, McElwee JJ, Smyth MJ, Casanova JL, Cooper AM, et al. IL-12 and IL-23 cytokines: from discovery to targeted therapies for immune-mediated inflammatory diseases. Nat Med. 2015;21(7):719-29. https://doi.org/10.1038/nm.3895.

33. Ohyama Y, Nakamura S, Matsuzaki G, Shinohara M, Hiroki A, Fujimura T, et al. Cytokine messenger RNA expression in the labial salivary glands of patients with Sjogren's syndrome. Arthritis Rheum. 1996;39(8):1376-84 https://doi.org/10.1002/art.1780390816.

34. Lodde BM, Mineshiba F, Kok MR, Wang J, Zheng C, Schmidt M, et al. NOD mouse model for Sjogren's syndrome: lack of longitudinal stability. Oral Dis. 2006;12(6):566-72. https://doi.org/10.1111/j.1601-0825.2006.01241.x.

35. Szodoray P, Alex P, Brun JG, Centola M, Jonsson R. Circulating cytokines in primary Sjogren's syndrome determined by a multiplex cytokine array system. Scand J Immunol. 2004;59(6):592-9. https://doi.org/10.1111/j.03009475.2004.01432.x

36. Bianco P. "Mesenchymal" stem cells. Annu Rev Cell Dev Biol. 2014;30:677704. https://doi.org/10.1146/annurev-cellbio-100913-013132.

37. Consentius C, Akyuz L, Schmidt-Lucke JA, Tschope C, Pinzur L, Ofir R, et al. Mesenchymal stromal cells prevent allostimulation in vivo and control checkpoints of Th1 priming: migration of human DC to lymph nodes and NK cell activation. Stem Cells. 2015;33(10):3087-99. https://doi.org/10.1002/stem.2104.

38. Akiyama K, Chen C, Wang D, Xu X, Qu C, Yamaza T, et al. Mesenchymalstem-cell-induced immunoregulation involves FAS-ligand-/FAS-mediated $T$ cell apoptosis. Cell Stem Cell. 2012;10(5):544-55. https://doi.org/10.1016/j. stem.2012.03.007.

39. Cho D-I, Kim MR, Jeong $\mathrm{H}-\mathrm{Y}$, Jeong $\mathrm{HC}$, Jeong $\mathrm{MH}$, Yoon $\mathrm{SH}$, et al. Mesenchymal stem cells reciprocally regulate the M1/M2 balance in mouse bone marrow-derived macrophages. Exp Mol Med. 2014;46. https://doi.org/ 10.1038/emm.2013.135.

40. Liu X, Ren S, Qu X, Ge C, Cheng K, Zhao RC. Mesenchymal stem cells inhibit Th17 cells differentiation via IFN-gamma-mediated SOCS3 activation. Immunol Res. 2015;61(3):219-29. https://doi.org/10.1007/s12026-014-8612-2.

41. Ramasamy R, Fazekasova H, Lam EW, Soeiro I, Lombardi G, Dazzi F. Mesenchymal stem cells inhibit dendritic cell differentiation and function by preventing entry into the cell cycle. Transplantation. 2007;83(1):71-6. https:// doi.org/10.1097/01.tp.0000244572.24780.54.

42. Nauta AJ, Kruisselbrink AB, Lurvink E, Willemze R, Fibbe WE. Mesenchymal stem cells inhibit generation and function of both CD34+-derived and monocyte-derived dendritic cells. J Immunol. 2006;177(4):2080-7.

43. Zhang Y, Cai W, Huang Q, Gu Y, Shi Y, Huang J, et al. Mesenchymal stem cells alleviate bacteria-induced liver injury in mice by inducing regulatory dendritic cells. Hepatology. 2014;59(2):671-82. https://doi.org/10.1002/hep.26670.

44. Shi D, Wang D, Li X, Zhang H, Che N, Lu Z, et al. Allogeneic transplantation of umbilical cord-derived mesenchymal stem cells for diffuse alveolar hemorrhage in systemic lupus erythematosus. Clin Rheumatol. 2012;31(5): 841-6. https://doi.org/10.1007/s10067-012-1943-2.

45. Sun $L$, Wang $D$, Liang J, Zhang $H$, Feng $X$, Wang $H$, et al. Umbilical cord mesenchymal stem cell transplantation in severe and refractory systemic lupus erythematosus. Arthritis Rheum. 2010;62(8):2467-75. https://doi.org/10, 1002/art.27548.

46. Li X, Wang D, Lu Z, Chen J, Zhang H, Sun L. Umbilical cord mesenchymal stem cell transplantation in drug-induced Stevens-Johnson syndrome. J Eur Acad Dermatol Venereol. 2013;27(5):659-61. https://doi.org/10.1111/j.14683083.2012.04572.x

\section{Ready to submit your research? Choose BMC and benefit from:}

- fast, convenient online submission

- thorough peer review by experienced researchers in your field

- rapid publication on acceptance

- support for research data, including large and complex data types

- gold Open Access which fosters wider collaboration and increased citations

- maximum visibility for your research: over $100 \mathrm{M}$ website views per year

At BMC, research is always in progress.

Learn more biomedcentral.com/submissions 